\title{
The South-to-North Water Diversion Project: effect of the water diversion pattern on transmission of Oncomelania hupensis, the intermediate host of Schistosoma japonicum in China
}

You-Sheng Liang ${ }^{1,2^{*}+}$, Wei Wang ${ }^{1,2+}$, Hong-Jun $\mathrm{Li}^{1,2}$, Xue-Hui Shen ${ }^{3}$, Yong-Liang $\mathrm{Xu}^{1,2}$ and Jian-Rong Dai ${ }^{1,2^{*}}$

\begin{abstract}
Background: The South-to-North Water Diversion Project (SNWDP) is the largest national water conservancy project in China. However, the Eastern Route Project (ERP) of SNWDP will refer to the habitats of Oncomelania hupensis, the intermediate host of Schistosoma japonicum. The present study was aimed at investigating the effects of some factors relating to the water diversion pattern on the spread north of $O$. hupensis and transmission of $S$. japonicum.
\end{abstract}

Methods: Marked snails were attached to the floating debris, and then placed on the water surface, the passage of snails through water pumps was observed. Some marked living adult snails were placed under water in the 5 spots, 15, 30, 60, 90 and 120 days later, their survival and transfer under water were investigated. 2, 4, 8, 16, 32, 64 and 128 juvenile snails, with a male: female ratio of about 1, were caged, 1 year later, their reproductions were calculated.

Results: The snails attached on the floating debris at 100-, 50- and 20-cm-distance from the inlet pipe of the big pump (with a diameter of $80 \mathrm{~cm}$ ), could be absorbed into the pumps, with passing rates of $2.45 \%, 3.93 \%$ and 43.46\%, respectively, compared with $72.07 \%$ and $91.00 \%$ for the snails at $20 \mathrm{~cm}$ and $10 \mathrm{~cm}$-distance from the inlet pipe of the small pump (with a diameter of $20 \mathrm{~cm}$ ). A total of 36,600 marked living snails were put into 5 ponds and ditches, with the water depths of 1-1.6 m, 15-120 days later, no marked ones were found along the ponds and ditches or in the straw packages. The juvenile snails did not reproduce until their density reached up to 8 snails (ratio of male: female of 1) $/ 0.16 \mathrm{~m}^{2}$.

Conclusions: During the construction of ERP of SNWDP, the risk of northward spread of schistosomiasis japonica will be decreased or eliminated as long as long-term reliable interventions for snail control are implemented.

Keywords: Schistosoma japonicum, Schistosomiasis japonica, The South-to-North Water Diversion Project, Oncomelania hupensis, Transmission, Spread, Diversion pattern, China

\footnotetext{
* Correspondence: wxliangyousheng@yahoo.cn; wxdaijianrong@yahoo.cn

† Contributed equally

${ }^{1}$ Jiangsu Institute of Parasitic Diseases, 117 Yangxiang, Meiyuan, Wuxi

214064, People's Republic of China

Full list of author information is available at the end of the article
} 


\section{Background}

Schistosomiasis is a snail-borne parasitic disease, which affects more than 207 million people in tropical and subtropical regions [1]. In China, schistosomiasis japonica remains endemic in lake regions of five provinces along the lower and middle reaches of the Yangtze River, and in some mountainous regions of Yunnan and Sichuan provinces. Currently, about 0.7 million people living in China are thought to have this disease $[2,3]$. Oncomelania hupensis, the amphibious intermediate host of Schistosoma japonicum, is only found in the Chinese mainland at latitudes below $33^{\circ} 15 \mathrm{~N}$ [4]. As the geographical distribution of $O$. hupensis defines the areas in China where S. japonicum is endemic, control of this snail is currently one of the main approaches used in attempts to interrupt the transmission of the disease [5-10].

The South-to-North Water Diversion Project (SNWDP), the key, national water-conservancy project currently under construction in China, has been designed to optimize the use of the limited water resources in China, and relieve water shortages in the north of the country [11]. The start of one of the main water intakes for the project, that of the Eastern Route Project (ERP), is located in Jiangdu County of Jiangsu Province, in an area heavily infested with $O$. hupensis [12]. The route of ERP will cross Baoying County (at $33^{\circ} 15 \mathrm{~N}$ ), the current northern limit of O. hupensis in the Chinese mainland [13], and then pass northward into non-endemic areas where the snail is now unknown. Following the completion of the project, whether the $O$. hupensis will be carried northward with the water flow, and lead to re-emergence of $O$. hupensis along the route of ERP and their new, more northern habitats and of the resultant expansion of S. japonicum endemicity to areas of China north of $33^{\circ} 15 \mathrm{~N}$, is the subject of much research [11,14-18].

$O$. hupensis, the only endemic intermediate host of $S$. japonicum in China, is both stenothermal and amphibious. Although the adult Oncomelania snails are able to live either on wet soil in the riverbank or in water, they are also mostly spread via water, usually on floating debris. While juvenile snails are entirely aquatic and are spread via water from the upper to lower reaches [13]. Wang and colleagues [11] set up caged populations of $O$. hupensis in Xuzhou $\left(34^{\circ} 23 \mathrm{~N}\right)$ and Jining $\left(35^{\circ} 23 \mathrm{~N}\right)$, two areas north of $33^{\circ} 15 \mathrm{~N}$, along the route of the ERP, and found that the snail populations could survive and reproduce in these areas, and retained their infectivity to S. japonicum. However, unlike the natural water flow, the ERP makes use of multi-stage pumping stations for diverting water from the south with low elevation to the north of the country with high elevation [12,19] (Figure 1). The aim of the present study was to investigate, during the multi-stage pumping water, the passage of snails through the pumps, the survival of the unattached snails and the reproduction of snails at different densities, so as to provide evidence for assessment of safe operation of SNWDP and implementation of scientific prevention and control interventions.

\section{Methods}

\section{Study areas}

For the experiment of snail movement under water, the study focused on 5 areas. Spot 1 was a fish pond in Gaozi Town, Dantu District of Zhenjiang City, measuring $145 \mathrm{~m} \times 60 \mathrm{~m}$ (water depth of $1.6 \mathrm{~m}$ ), without weeds or aquatic plants. Spot 2 was a natural pond with an area of $120 \mathrm{~m} \times 51 \mathrm{~m}$ (water depth of $1.5 \mathrm{~m}$ ) in Gaozi Town, Dantu District of Zhenjiang City, and no aquatic plants were found. Spot 3 was a rectangular pond (size of $50 \mathrm{~m} \times 70 \mathrm{~m}$, water depth of $1 \mathrm{~m}$ ) in Shiye Town, Dantu District of Zhenjiang City, without aquatic plants. Spot 4 was a ditch with an area of $200 \mathrm{~m}$ $\times 2 \mathrm{~m}$ and a depth of $1.2 \mathrm{~m}$ in Shiye Town, Dantu District of Zhenjiang City, no aquatic plants were present. Spot 5 was an irregular pond with a depth of $1.2 \mathrm{~m}$ in Shiye Town, Dantu District of Zhenjiang City, and no aquatic plants were found. All of the 5 areas are currently endemic for S. japonicum, where O. hupensis are distributed in surrounding ponds or ditches.

For the experiment of snail reproduction, a pond with an area of $825.8 \mathrm{~m}^{2}$ was selected in Xinmin Marshland, Gaoyou City of Jiangsu Province $\left(32^{\circ} 42.8\right.$ N, $119^{\circ} 23.6$ $\mathrm{N})$, which was, historically, an endemic area, and currently is still a snail habitat with low density.

\section{Snails}

O. hupensis snails were collected from the rural marshland of Dantu District, Zhenjiang City by picking them up with forceps. Snails were transferred to the laboratory and raised for 2 weeks at a temperature of $25^{\circ} \mathrm{C}$. Each snail was tested twice for natural infection using the cercarial shedding method [20]. Since none of the snails had natural infections, active adult snails with $6 \sim 7$ whorls were used. Then each snail was marked in red or green color on the apex using a TOYO marker for the subsequent experiments. A snail with a length of $<5 \mathrm{~mm}$ was defined as juvenile, each juvenile snail was separated into male and female by microscopical examination, and then was used for the subsequent experiments.

\section{Snail cages}

Cages containing wild-caught, juvenile $O$. hupensis were set up at the study site for investigation of the effect of the snail density on reproduction of O. hupensis. Each cage was a cube measuring $40 \mathrm{~cm} \times 40 \mathrm{~cm} \times 40 \mathrm{~cm}$, made of a strong frame of iron wire covered in wire 


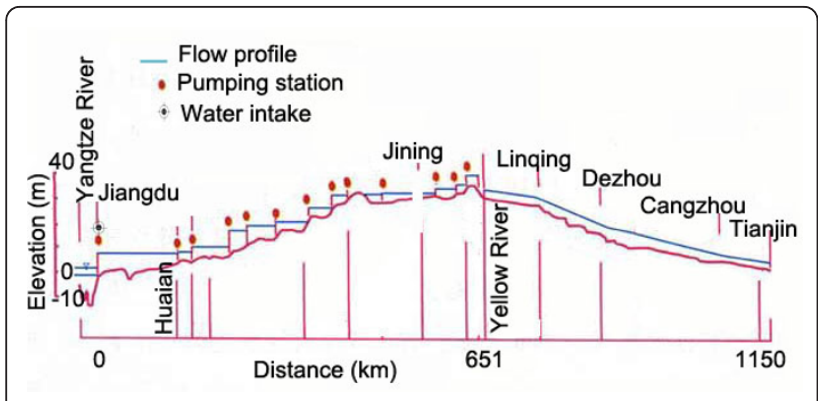

Figure 1 The diversion route of the Eastern Route Scheme of the South-to-North Water Diversion Project.

netting (with a mesh size of $1.18 \mathrm{~mm}$ ). A piece of nylon gauze (with a mesh size of $0.12 \mathrm{~mm}$ ) was placed across the bottom of each cage to support a 10-cm-thick layer of unpolluted local soil.

\section{Pumps}

Two types of pumps were used in the present study. The bigger one was $80 \mathrm{~cm}$ in diameter and $585 \mathrm{r} / \mathrm{min}$ in rotational speed, with a power of $80 \mathrm{~kW}$. Another was $20 \mathrm{~cm}$ in diameter and $7.5 \mathrm{~kW}$ in power.

\section{Tucknets}

Two coniform tucknets were made for collecting the snails that passed through the pumps. The bottom of the both tucknets was made of a strong frame of circular iron wire (with diameters of 85 and $22 \mathrm{~cm}$ ), which were covered with nylon gauze with a mesh size of $0.12 \mathrm{~mm}$.

\section{Straw packages}

Some straw packages, each weighing $0.5 \mathrm{~kg}$, were made to attract snails.

\section{Snails passing through the pumps}

A total of 30,000 marked snails were attached to the floating debris, 6,000 in each position, and then placed on the water surface at 100-50- and 20-cm-distance from the inlet pipe of the big pump, and 20- and 10$\mathrm{cm}$-distance from the inlet pipe of the small pump. Following switching on the pumps, the attached snails would be absorbed into pumps. The tucknets were fixed onto the outlet pipe of the pumps to collect snails.

\section{Snail movement under water}

From 24th, June to 13th, October 2007, a total of 8400 marked snails were placed at the site, $10 \mathrm{~m}$ from the north bank and $20 \mathrm{~m}$ from the east bank in Spot 1, 6,200 marked snails were placed at the site $2 \mathrm{~m}$ from the east bank and $5 \mathrm{~m}$ from the north bank in Spot 2, 5,000 marked snails were placed at the site $3 \mathrm{~m}$ from the north bank and $5 \mathrm{~m}$ from the west bank in Spot 3, 5,000 marked snails were placed at the site $1 \mathrm{~m}$ from the bank in Spot 4, 12,000 marked snails were placed at the site $5 \mathrm{~m}$ and $6 \mathrm{~m}$ from the west bank in Spot 5 , each containing 6,000. Straw packages were placed on the water surface of all spots at a distance interval of 10 m. 15, 30, 60, 90 and 120 days later, the marked snails were collected along the pond and ditch bank. The straw packages floating on the water surface were also collected to check the presence of the marked snails.

\section{Effect of snail density on reproduction}

$2,4,8,16,32,64$ and 128 juvenile snails, with a male: female ratio of about 1 , were put into snail cages and then sealed with iron. Each cage was placed beside the pond, with the base at an angle of $30^{\circ}$ from horizontal, so that a third of the soil layer in the cage was immersed in water. One year later, all cages were removed from the study site, and the snails in the cages were recovered, by sifting the soil in the cages through an 830-m-mesh brass sieve. Those suspected of being dead were tested by observing their responses to being tapped. Reproduction of the snails was recorded.

\section{Ethical approval}

This study was approved by the Ethics Review Committee of Jiangsu Institute of Parasitic Diseases, China (Permission number: JIPDERC2007008).

\section{Results}

\section{Snails passing through the pumps}

The snails, attached to the floating debris, at 100, 50 and 20 $\mathrm{cm}$ from the inlet pipe of the big pump, could be absorbed into the pumps, with passing rates of $2.45 \%$ (147/6000), $3.93 \%(236 / 6000)$ and $43.46 \%(2608 / 6000)$, respectively. The attached snails at 20 and $10 \mathrm{~cm}$ from the inlet pipe of the small pump could also be absorbed, with passing rates of $72.07 \%$ (4324/6000) and $91.00 \%$ (5460/6000), respectively. It is indicated that a higher possibility of snails passing through the pumps is observed as the initial snail placement distance from the inlet pipe decreases.

\section{Snail transfer under water}

A total of 36,600 marked living snails were put in the 5 study areas, 15, 30, 60, 90 and 120 days later, no marked snails were found along the pond and/or ditch bank. There were also no snails found in the straw packages. However, on February of the following year, there were many dead marked snails found in the mud near the snail throwing sites of spots 4 and 5 .

\section{Reproduction of snails with different densities}

$2,4,8,16,32,64$ and 128 juvenile snails were put into snail cages with a male: female ratio of about 1 , one year later, snails did not reproduce until densities reached up to 8 snails $/ 0.16 \mathrm{~m}^{2}$ (Table 1 ). 
Table 1 Reproduction of juvenile snails with different densities of breeding for 1 year in the field

\begin{tabular}{|c|c|c|c|c|c|c|}
\hline \multirow{2}{*}{$\begin{array}{l}\text { Juvenile snails (male: female ratio of } 1 \text { ) } \\
\text { with different densities (snails/0.16 } \mathrm{m}^{2} \text { ) }\end{array}$} & \multicolumn{3}{|l|}{ Group I } & \multicolumn{3}{|l|}{ Group II } \\
\hline & $\begin{array}{l}\text { No. snails } \\
\text { collected }\end{array}$ & $\begin{array}{l}\text { No. living } \\
\text { snails }\end{array}$ & $\begin{array}{l}\text { Reproduction } \\
\text { (\%) }\end{array}$ & $\begin{array}{l}\text { No. snails } \\
\text { collected }\end{array}$ & $\begin{array}{l}\text { No. living } \\
\text { snails }\end{array}$ & $\begin{array}{l}\text { Reproduction } \\
(\%)\end{array}$ \\
\hline 2 & 2 & 1 & -50 & 1 & 1 & -50 \\
\hline 4 & 3 & 3 & -25 & 3 & 1 & -75 \\
\hline 8 & 30 & 21 & 162.5 & 35 & 27 & 237.5 \\
\hline 16 & 49 & 43 & 168.8 & 51 & 47 & 193.8 \\
\hline 32 & 58 & 51 & 59.4 & 63 & 56 & 75 \\
\hline 64 & 118 & 108 & 68.8 & 121 & 110 & 71.9 \\
\hline 128 & 229 & 197 & 53.9 & 243 & 201 & 57 \\
\hline
\end{tabular}

\section{Discussion}

Schistosomiasis is a snail-transmitted, water-borne devastating neglected tropical disease $[21,22]$. In China, schistosomiasis japonica is endemic in 7 provinces with about 0.7 million people infected with the causative agent, S. japonicum [2]. Historically, the geographic distribution of the disease was restricted south to the $33^{\circ}$ $15^{\prime} \mathrm{N}$ latitude, governed by the distribution of its intermediate host snail, i.e. O. hupensis [4,13]. Unlike Biomphalaria and Bulinus snails that are entirely aquatic, $O$. hupensis is both stenothermal and amphibious. There were several studies reporting the transmission intensification or introduction of schistosomiasis into non-endemic areas following water resource development [23-27]. Considering schistosomiasis is widely distributed and the infection rates can change promptly, it is considered as a sensitive indicator disease for monitoring ecological transformation [28]. Steinmann and colleagues [1] conducted a systematic literature review and meta-analysis in 58 studies which attempt to examine the relation between water resource development projects and schistosomiasis, and it is concluded that the development and management of water resources is an important risk factor for schistosomiasis.

SNWDP is currently the largest water resource development project under construction in China [11]. Not only is the water intake of the ERS located in an $O$. hupensis habitat, but the route of the completed ERS will cross many other historical breeding sites for this species, to the north where the disease is currently not endemic $[12,13]$. The impact of ERP of on the transmission of S. japonicum in China is focused on the effects on distribution of $O$. hupensis [14,29,30], which includes 3 key points, absorption of snails into water-diversion route by the pumps, movement and survival of snails that fall into water, and the reproduction of low-density snails and formation of new populations. The possibility that, by carrying the intermediate host northwards, the SNWDP will lead to a northern expansion of schistosomiasis japonica in China has therefore been investigated
[29-36]. Survival and reproduction of snails in areas north of $33^{\circ} 15 \mathrm{~N}$ has also been reported [11,37-39], however, the assessment of the impact of the spread of snails remains unclear. The study described here, therefore, was designed to investigate whether the attached snails on the floating debris fell into the river course and then entered into the next stage, the possibility that the unattached snails survived in deep water and then moved to the riverbank, and the reproduction of snails at different densities in field simulated experiments.

Our findings showed that, if the snails were absorbed into the pumps, they would the pass through the pumps. The percentage of snails passing through the pumps was associated with the snails entering into the inlet pipes. While the snails were put into a distant point from the inlet pipe, they were more affected by the rotating eddy current effect induced by the water flow during the movement of floating debris to the inlet pipe, resulting in the snails being more likely to be separated from the floating debris. Therefore, snail control interventions should be implemented around the water intake to reduce the snail density and decrease the possibility of snails entering the water-source area via floating debris. In addition, the hydraulic structures constructed in water intake and on the water-diversion route, such as flood-gates, fences and stilling pools, would cause the sedimentation of many snails, and decrease the risk of snails being absorbed into pumps [12,15,19,40-44].

In the multi-stage pumped water, under the effect of pumps, the adult snails were separated from the floating debris and fell into the deep water while passing through the pumps. Whether the unattached snails can survive in the deep water and transfer to the bank, is an important ecological issue. It has been reported that, dyed snails were put into a streamlet, and 4 days later, they were found along the water line [45]. However, our present findings showed that, a total of 36,600 marked living snails were put into 5 spots and 4 types of water body at different times (from June to October), after a 
period of 120 days, there were no marked living snails found along the pond or ditch bank or in the straw packages, but plenty of marked dead snails were found in the mud of the dried study areas. Adult O. hupensis, an amphibious and freshwater species, hardly ever survives and reproduces under water $[13,46,47]$. The current study showed that although adult $O$. hupensis can move via foot [13], generally the adults rarely transfer to the bank and survive. It has also been indicated that there were no snails found in the fence of the pumping station and the water-transporting channel in Jiangdu pumping station, the water intake of ERP [40]. Further study should be carried out to investigate the effect of environmental differences between the streamlet and pond on the spread of snails.

Juvenile $O$. hupensis snails are entirely aquatic and are spread via water [13]. There is currently no sufficient evidence to prove the threshold of the snail density for reproduction to new snail habitat. Our present study indicates that snails are likely to be reproduced to form a new population when the density of the juvenile snails reaches 8 snails (ratio of male to female is 1 ) $/ 0.16 \mathrm{~m}^{2}$. However, this is only a preliminary finding, future experiments should be conducted for further verification.

Overall, it is thought that, inevitably, although the attached snails will enter into the river course during the multi-stage pumped water of ERP of SNWDP, under the effect of pumps, the attached snails will be separated from the floating debris, and fall into the deep water, and result in a small possibility of transferring to the bank and survival. In addition, the hydraulic structures constructed on the water-diversion route, such as floodgates, fences and stilling pools, will cause the sedimentation of many snails, again restricting the spread of adult snails via the pumped water $[12,40,41]$. Juvenile snails are spread via water, and reproduce while reaching a certain density.

\section{Conclusions}

During the construction of ERP of SNWDP, it is very likely to reduce or eliminate the risk of snail spread north if effective snail control interventions are implemented to control snail spread and reduce snail density.

\footnotetext{
Acknowledgements

This project was supported by the National Important Sci-Tech Special Projects (2008ZX10004-011), the National Science \& Technology Pillar Program of China (2009BAl78B06), the National Natural Science Foundation of China (81071379), the Jiangsu Province's Outstanding Medical Academic Leader Program (LJ201132), the Jiangsu Provincial Department of Health (X200901 and X201103), the Jiangsu Provincial Scientific Foundation of Preventive Medicine (Y201031) and the Jiangsu Society for Editors of Scientific and Technical Periodicals (JKQJX006). We sincerely thank Professor Xiao-Nong Zhou for his kind comments on the drafted manuscript.
}

\section{Author details}

${ }^{1}$ Jiangsu Institute of Parasitic Diseases, 117 Yangxiang, Meiyuan, Wuxi 214064, People's Republic of China. ${ }^{2}$ Key Laboratory on Technology for Parasitic Disease Prevention and Control, Ministry of Health, 117 Yangxiang, Meiyuan, Wuxi 214064, Jiangsu Province, People's Republic of China. ${ }^{3}$ Dantu District Center for Disease Control and Prevention, 171 Guyang Avenue, Danyang, Zhenjiang City 212028, Jiangsu Province, People's Republic of China.

\section{Authors' contributions}

YSL, WW and JRD conceived and designed the study. YSL and JRD collected baseline data. X.H.S. provided logistical support for part of the fieldwork. YSL, WW, HJL, XHS, YLX and JRD took part in all of the fieldwork. WW carried out the statistical analysis and interpretation of the data and prepared the manuscript. YSL and JRD revised the manuscript. All authors read and approved the final manuscript.

\section{Competing interests}

The authors declare that they have no competing interests.

Received: 14 August 2011 Accepted: 20 March 2012

Published: 20 March 2012

\section{References}

1. Steinmann P, Keiser J, Bos R, Tanner M, Utzinger J: Schistosomiasis and water resources development: systematic review, meta-analysis, and estimates of people at risk. Lancet Infect Dis 2006, 6:411-425.

2. Zhou XN, Guo JG, Wu XH, Jiang QW, Zheng J, Dang H, Wang XH, Xu J, Zhu HQ, Wu GL, Li YS, Xu XJ, Chen HG, Wang TP, Zhu YC, Qiu DC, Dong XQ, Zhao GM, Zhang SJ, Zhao NQ, Xia G, Wang LY, Zhang SQ, Lin DD, Chen MG, Hao Y: Epidemiology of schistosomiasis in the People's Republic of China, 2004. Emerg Infect Dis 2007, 13:1470-1476.

3. Li SZ, Luz A, Wang XH, Xu LL, Wang Q, Qian YJ, Wu XH, Guo JG, Xia G, Wang $L Y$, Zhou $X N$ : Schistosomiasis in China: acute infections during 2005-2008. Chin Med J (Engl) 2009, 122:1009-1014

4. Mao CP: Biology of Schistosome and Control of Schistosomiasis Beijing: People's Medical Publishing House; 1990, (in Chinese).

5. Yuan $Y, X u$ XJ, Dong HF, Jiang MS, Zhu HG: Transmission control of schistosomiasis japonica: implementation and evaluation of different snail control interventions. Acta Trop 2005, 96:191-197.

6. Zhou XN, Wang LY, Chen MG, Wu XH, Jiang QW, Chen XY, Zheng J, Utzinger J: The public health significance and control of schistosomiasis in China-then and now. Acta Trop 2005, 96:97-105.

7. Zhou XN, Bergquist R, Leonardo L, Yang GJ, Yang K, Sudomo M, Olveda R: Schistosomiasis japonica control and research needs. Adv Parasitol 2010, 72:145-178.

8. Wang LD, Utzinger J, Zhou XN: Schistosomiasis control: experiences and lessons from China. Lancet 2008, 372:1793-1795.

9. Wang LD, Guo JG, Wu XH, Chen HG, Wang TP, Zhu SP, Zhang ZH, Steinmann $P$, Yang GJ, Wang SP, Wu ZD, Wang LY, Hao Y, Bergquist R, Utzinger J, Zhou XN: China's new strategy to block Schistosoma japonicu transmission: experiences and impact beyond schistosomiasis. Trop Med Int Health 2009, 14:1475-1483.

10. Li SZ, Wang YX, Yang K, Liu Q, Wang Q, Zhang Y, Wu XH, Guo JG, Bergquist $\mathrm{R}$, Zhou $\mathrm{XN}$ : Landscape genetics: the correlation of spatial and genetic distances of Oncomelania hupensi, the intermediate host snail of Schistosoma japonicu in mainland China. Geospat Health 2009, 3:221-231.

11. Wang W, Dai JR, Liang YS, Huang YX, Coles GC: Impact of the South-toNorth Water Diversion Project on the transmission of Schistosoma japonicu in China. Ann Trop Med Parasitol 2009, 103:17-29.

12. Huang $Y X$, Tian ZZ, Sun LP, Hong QB, Gao Y, Wu F: Impact of project diverting Yangtze River water to Northern Jiangsu on transmission towards north of Oncomelania hupensi snails. Chin J Schisto Control 2005, 17:184-189, (in Chinese).

13. Zhou XN: Science of Oncomelania Snail Beijing: Science Press; 2005, (in Chinese).

14. Xiao RW, Sun QQ, Chen YT: Does the South-to-North Water Diversion Project lead to the spread of Oncomelani snails to the North? Geograph Res 1982, 1:73-79, (in Chinese).

15. Zhou XN, Wang LY, Zheng J, Guo JG, Zhao YJ, Liao HY, Huang SS, Zhu YC, Xu XJ, Cai G, Gao Y, Liang YS, Zhang XB, Huang YX: Potential impact of 
South-north Water Transfer Project on transmission and distribution of schistosomiasis japonica. Chin J Schisto Control 2003, 15:294-297, (in (hinese).

16. Yang GJ, Vounatsou P, Zhou XN, Tanner M, Utzinger J: A potential impact of climate change and water resource development on the transmission of Schistosoma japonicu in China. Parassitologia 2005, 47:127-134.

17. Yang GJ, Vounatsou P, Tanner M, Zhou XN, Utzinger J: Remote sensing for predicting potential habitats of Oncomelania hupensi in Hongze, Baima and Gaoyou lakes in Jiangsu province, China. Geospat Health 2006, 1:85-92.

18. Yang GJ, Gemperli A, Vounatsou P, Tanner M, Zhou XN, Utzinger J: A growing degree-days based time-series analysis for prediction of Schistosoma japonicu transmission in Jiangsu province, China. AmJTrop Med Hyg 2006, 75:549-555.

19. Huang $Y X$, Sun $L P$, Hang DR, Hong QB, Gao Y, Zhang JF, Gao JB, Chen YJ, Zhu XZ, Zhu XG: Characteristics of engineering and diversion water and their potential effect on schistosomiasis japonica transmission in east route of South-to-North Water Diversion Project. Chin J Schisto Control 2009, 21:382-388, (in Chinese).

20. MOH: Handbook for Schistosomiasis Shanghai: Shanghai Science \& Technology Press; 2000, in Chinese.

21. Gryseels B, Polman K, Clerinx J, Kestens L: Human schistosomiasis. Lancet 2006, 368:1106-1118.

22. Chitsulo L, Loverde P, Engels D: Schistosomiasis. Nat Rev Microbiol 2004, 2:12-13.

23. Ernould JC, Ba K, Sellin B: The impact of the localwater2development programme on the abundance of the intermediate hosts of schistosomiasis in three villages of the Senegal River delta. Ann Trop Med Parasitol 1999, 93:135-145.

24. Hunter JM, Rey L, Scott D: Man-made lakes and man-made diseases. Towards a policy resolution. Soc Sci Med 1982, 16:1127-1145.

25. Southgate VR: Schistosomiasis in the Senegal River Basin: before and after the construction of the dams at Diama, Senegal and Manantali, Mali and future $\mathrm{p}$ rospects. J Helminthol 1997, 71:125-132.

26. Jobin WR: Dams and Disease. Ecological Design and Health Impacts of Large Dams, Canals and Irrigation Systems London: E \& F N Spon; 1999.

27. Oladejo SO, Ofoezie IE: Unabated schistosomiasis transmission in Erinle RiverDam, Osun State, Nigeria: evidence of neglect of environmental effects of development $\mathrm{p}$ rojects. Trop Med Int Health 2006, 11:843-850

28. Huang $Y X$, Manderson $\mathrm{L}$ : Schistosomiasis and the social patterning of infection. Acta Trop 1992, 51:175-194

29. Wang TP, Zhang SQ: Relationship between the South-to-North Water Diversion Project and snails spread and schistosomiasis transmission. Chin J Epidemiol 2002, 33:87-89, (in Chinese).

30. Wang W, Liang YS, Dai JR, Huang YX: Impact of the construction of the South-to-North Water Diversion Project on distribution of Oncomelania hupensi, the intermediate host of Schistosoma japonicu. Acta Ecol Sin 2008, 28:4235-4245, (in Chinese).

31. Zhang BY: Can the South-to-North water transfer project induce the spread of snails to the north? Pop Sci 1994, 1:14-15, (in Chinese).

32. Wang HF, Wen YQ, Zhong WX: South-north Water Diversion Project and schistosomiasis spreading. Chin J Schisto Control 2007, 19:238-240, (in (hinese).

33. Gu F: The South-to-North Water Diversion Project: with the consideration of the schistosomiasis spreading to the North of China Med Health Care 2005, 13:35, (in Chinese).

34. Shi Y: Thinking about the snail spread during the construction of the South-to-North Water Diversion Project. Sci Tech Info Gansu 2004, 33:183-184, (in Chinese).

35. Miu F, Yang GH, Zhao B: Impact of the South-north Water Diversion Project on schistosomiasis transmission and control strategy. Bull Biol 2004, 39:18-20, (in Chinese).

36. Miu F, Fu ZY: The South-to-North Water Diversion Project and schistosomiasis. Chin J Parasit Dis Control 2005, 18:235-236, (in Chinese).

37. Liang YS, Xiao RW, Song HT, Dai JR, Jiang BQ, Miao F, Zhu JS, Zhu YG, Ye JF, Cheng ZM: Field observation on the survival and multiplication of Oncomelani snails in the different latitude regions in China. Chin J Schisto Control 1996, 8:259-262, (in Chinese).

38. Miu F, Wen PE, Zhao ZP, Liu X, Wan GQ, Liang YS: Study on the surviving ability of Oncomelani snails in Jinin of Shandong Province. Chin J Parasit Dis Control 2000, 13:VI-VII, in Chinese.
39. Miu F, Li WQ, Liu YC, Wen PE: Study on the viability of Oncomelania hupensi on irrigation network in Shandong Province after reversion of Yangtze River to Arid northern part of China. Chin Trop Med 2003, 3:292-294, (in Chinese).

40. Huang YX, Gao Y, Hong QB, Sun LP, Yang K, Li W, Zhang JF, Zhu XZ, Zhu XG, Liang YS: Observation on Oncomelania hupensi spread in Jiangdu pumping station in the east route of South-north Water Diversion Project. Chin J Schisto Control 2006, 18:247-251, (in Chinese).

41. Huang YX, Xu ZK, Ren ZY, Tian ZZ, Yang Z, Gao Y, Hong QB, Sun LP, Hang DR, Liang YS: Impact of water flow on transmission towards north of Oncomelania hupensi after the first phase of the east route of Southto-North Water Diversion Project. Chin J Schisto Control 2007, 19:91-97, (in (hinese).

42. Huang YX, Ren ZY, Hang DR, Hong QB, Gao Y, Guo JH, Sun DK, Zuo YP: Potential effect of climate changes on schistosomiasis japonica transmission in east route of South-to-North Water Diversion Project. Chin J Schisto Control 2009, 21:197-204, (in Chinese).

43. Huang YX, Zuo YP, Hang DR, Sun DK, Li W, Guo JH, Zhang JF, Zhu XG, Ma YC, Gao JB, Zheng B, Tang HP, Gao Y: Study on surveillance and earlywarning system of schistosomiasis in first phase of the east route of South-to-North Water Diversion Project I Layout of Oncomelania hupensi surveillance sites. Chin J Schisto Control 2010, 22:339-345, (in Chinese).

44. Zuo YP, Sun DK, Huang YX, Gao Y, Guo JH, She GS, Gao JB, Hang DR, Ma YC, Zheng B, Li W, Zhang JF, Zhou HW, Tang HP: Study on surveillance and early-warning system of schistosomiasis in first phase of the east route of South-to-North Water Diversion Project I Surveillance of Oncomelania hupensi and schistosomiasis. Chin I Schisto Control 2010, 22:420-424, (in Chinese).

45. Su DL: Collection of theses of Professor Su Delong Tianjin: Tianjin Science \& Technology Press; 1995, (in Chinese).

46. Liang YS, Xiao RW, Song HT: Observations on the survival and multiplication of Oncomelani snails after winter flooding in marshland of Yangtze River. Chin J Zool 1994, 29:5-8, (in Chinese).

47. Liang YS, Xiong XK, Song HT, Xiao RW, Ye JF, Zhang JK, Fei FX: Histochemical and ultrastructural changes of Oncomelani snails after winter flooding in marshland of the Yangtze River. Chin J Zool 1994, 29:6-9, (in Chinese).

doi:10.1186/1756-3305-5-52

Cite this article as: Liang et al:: The South-to-North Water Diversion Project: effect of the water diversion pattern on transmission of Oncomelania hupensis, the intermediate host of Schistosoma japonicum in China. Parasites \& Vectors 2012 5:52.

\section{Submit your next manuscript to BioMed Central and take full advantage of:}

- Convenient online submission

- Thorough peer review

- No space constraints or color figure charges

- Immediate publication on acceptance

- Inclusion in PubMed, CAS, Scopus and Google Scholar

- Research which is freely available for redistribution

Submit your manuscript at www.biomedcentral.com/submit
C Biomed Central 